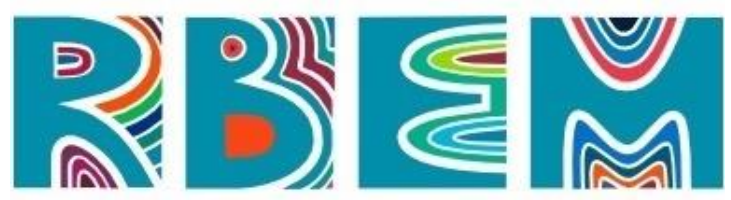

REVISTA BAIANA DE EDUCAÇÃO MATEMÁtICA

\title{
ARTIGO
}

do] https://doi.org/10.47207/rbem.v2i01.12397

\section{Estágio Curricular Supervisionado na Pandemia da Covid-19: (Re) pensando a formação inicial do professor de Matemática}

\author{
ANDRADE, Susimeire Vivien Rosotti \\ Universidade Estadual do Oeste do Paraná (UNIOESTE). Doutora em Educação Matemática pela Universidade \\ Federal do Mato Grosso do Sul. ORCID: https://orcid.org/0000-0001-9188-8620. \\ E-mail: susimeire.andrade@unioeste.br. \\ BEZERRA, Renata Camacho \\ Universidade Estadual do Oeste do Paraná (UNIOESTE). Doutora em Educação pela Universidade Estadual \\ Paulista "Júlio de Mesquita Filho". ORCID: https://orcid.org/0000-0002-4461-8473. \\ E-mail: renata.bezerra@unioeste.br \\ CAETANO, Richael Silva \\ Universidade Estadual do Oeste do Paraná (UNIOESTE). Doutor em Educação para a Ciência pela Universidade \\ Estadual Paulista "Júlio de Mesquita Filho". ORCID: https://orcid.org/0000-0002-9644-3847. \\ E-mail: richael.caetano@unioeste.br.
}

Resumo: A pandemia da Covid-19 ocasionou mudanças em toda a sociedade, inclusive nas instituições de ensino. Este artigo apresenta a (re) organização do Estágio Curricular Supervisionado, da Licenciatura em Matemática da Universidade Estadual do Oeste do Paraná (UNIOESTE) - campus Foz do Iguaçu, frente a esta realidade. A questão que norteia nossas reflexões é: Como o Estágio Curricular Supervisionado do curso de Licenciatura em Matemática, na UNIOESTE, se desenvolveu frente à pandemia da Covid-19? Para tanto, se apresenta uma pesquisa de abordagem qualitativa cujos procedimentos advêm da investigação bibliográfica e documental na qual analisa: a) Projeto Pedagógico do Curso (PPC); b) Regulamento de estágio; c) Planos de Ensino das disciplinas de Estágio I e II do ano letivo de 2020; d) Relatórios Finais dos alunos que realizaram o estágio no referido ano; e) Atas da reunião de Colegiado do Curso de Matemática do ano de 2020. A partir da análise dos dados, evidencia mudanças nas seguintes atividades que compõem o estágio curricular obrigatório: observação e/ou participação, regência e projeto, bem como na estrutura das aulas (síncronas/assíncronas) desenvolvidas, pois foram utilizadas plataformas de aprendizagem para a ocorrência das interações. Outras constatações referem-se às alterações dos trâmites legais que regulamentaram a realização dos estágios e que desencadearam mudanças na escolha das instituições de ensino para a realização do estágio, uma vez que os acadêmicos não puderam escolher a instituição como ocorria no ensino presencial. Enfim, para o desenvolvimento do estágio na conjectura pandêmica houve uma (re) organização em todas as atividades supracitadas.

Palavras-chave: Estágio Curricular Supervisionado. Pandemia da COVID-19. Formação Inicial de Professores de Matemática.

\section{Supervised Internship in the Covid-19 Pandemic: (re) thinking about the initial education of the mathematics teacher}

Abstract: The Covid-19 pandemic caused changes throughout society, including in educational institutions. This article presents the (re) organization of the Supervised 


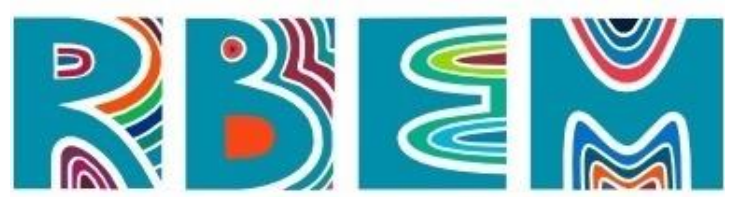

REVISTA BAIANA DE EDUCAÇÃO MATEMÁTICA

Internship, of the Degree in Mathematics of the State University of Western Paraná (UNIOESTE) - Foz do Iguaçu campus, facing this reality. The question that guides our reflections is: How did the Supervised Course Internship in Mathematics, at UNIOESTE, develop in the face of the Covid-19 pandemic? To this end, a qualitative approach research is presented whose procedures come from bibliographic and documentary research in which it analyzes: a) Pedagogical Project of the Course (PPC); b) Internship regulation; c) Teaching Plans for Stage I and II subjects of the school year 2020; d) Final Reports of students who completed the internship in that year; e) Minutes of the meeting of the College of the Mathematics Course of the year 2020. From the data analysis, we evidenced changes in the following activities that make up the mandatory curricular internship: observation and/or participation, conducting and design, as well as the structure of the classes developed for the realization of the disciplines given the need of the use of learning platforms for the occurrence of synchronous/asynchronous interactions. Other findings refer to changes in the legal procedures that regulated the completion of internships and that triggered changes in the choice of academics of educational institutions for the completion of the internship, since they could not choose the institution as it was happening in the classroom. Finally, for the development of the stage in the pandemic conjecture there was an (re) organization in all the above mentioned activities.

Keywords: Supervised Curricular Internship. Pandemic of COVID-19. Initial Training of Mathematics Teachers.

\section{Prácticas de estudios supervisadas en la pandemia de covid-19: (re) pensando en la formación inicial del profesor de matemáticas}

Resumen: La pandemia de Covid-19 ocasionó cambios en toda la sociedad, incluso en las instituciones educativas. Este artículo presenta la (re) organización de la Pasantía Curricular Supervisada, de la Licenciatura en Matemáticas de la Universidad Estatal del Oeste de Paraná (UNIOESTE) - campus Foz do Iguaçu, frente a esta realidad. La cuestión que guía nuestras reflexiones es: ¿Cómo se desarrolló la Pasantía Curricular Supervisada del curso de Licenciatura en Matemáticas, en la UNIOESTE, frente a la pandemia de Covid-19? Para ello, se presenta una investigación de abordaje cualitativo cuyos procedimientos se derivan de la investigación bibliográfica y documental en la que analiza: a) Proyecto Pedagógico del Curso (PPC); b) Reglamento de prácticas; c) planes de enseñanza de las disciplinas de prácticas I y II del año escolar 2020; d) informes finales de los alumnos que hayan realizado el período de prácticas en dicho año; e) actas de la reunión de la Colegiata del curso de matemáticas del año 2020. Del análisis de los datos, hemos mostrado cambios en las siguientes actividades que conforman la pasantía curricular obligatoria: observación y/o participación, regencia y diseño, así como en la estructura de las clases desarrolladas para la realización de las disciplinas dada la necesidad de la utilización de plataformas de aprendizaje para la ocurrencia de las interacciones síncronas/asíncronas. Otras constataciones se refieren a las alteraciones de los trámites legales que reglamentaron la realización de los pasantías y que desencadenaron cambios en la elección de los académicos de las instituciones de enseñanza para la realización del pasantía, ya que no pudieron elegir la institución como ocurría en la enseñanza y presencial. Finalmente, para el desarrollo de la etapa en la conjetura pandémica hubo una (re) organización en todas las actividades antes citadas.

Palavras-Clave: Pasantía Curricular Supervisado. Pandemia de COVID-19. Formación Inicial de Profesores de Matemáticas.

\section{Introdução}

O Estágio Curricular Obrigatório do Curso de Licenciatura em Matemática, da 


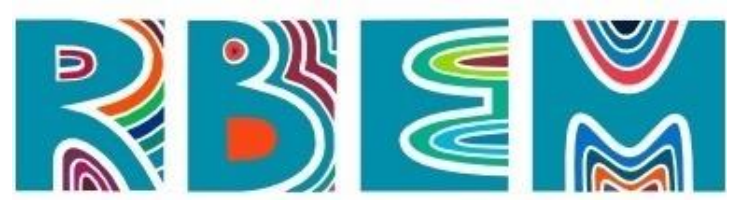

REVISTA BAIANA DE EDUCAÇÃO MATEMÁTICA

Universidade Estadual do Oeste do Paraná - UNIOESTE, campus Foz do Iguaçu era desenvolvido nas instituições de ensino públicas de forma presencial e supervisionado. No entanto, no início do ano de 2020, o nosso país teve que adotar o isolamento físico e social por conta da pandemia da Covid-19 e tal isolamento acarretou consequências à realização do referido estágio.

Praticamente durante o primeiro semestre do referido ano não se fez possível a realização das disciplinas do Curso. Contudo, no segundo semestre foi aberta a possibilidade da realização de disciplinas na forma remota, permitida pela Resolução n. ${ }^{\circ}$ 74/2020-CEPE. Assim, os autores deste artigo, sendo os professores das disciplinas de Estágio Supervisionado I e II, tiveram que se reinventar enquanto docentes e repensar a estrutura do Estágio Curricular Supervisionado considerando o que é estabelecido por Lei e a necessidade de realizá-lo remotamente. Embora essa não tenha sido uma experiência fácil, trouxe aprendizagens aos envolvidos alunos e professores.

Assim, a questão norteadora deste artigo é: "Como o Estágio Curricular Supervisionado do curso de Licenciatura em Matemática na UNIOESTE se desenvolveu frente à pandemia da Covid-19?". Enquanto objetivo pretende-se apresentar a (re) organização do Estágio Curricular Supervisionado da Licenciatura em Matemática da UNIOESTE frente a esta realidade.

Para tanto, socializaremos esta experiência apresentando uma pesquisa cuja abordagem é qualitativa de cunho bibliográfico e documental. A seguir, abordar-se-ão os seguintes itens: a) uma breve apresentação dos aspectos legais referentes à realização do estágio nos cursos de licenciatura; b) a análise do Projeto Pedagógico do Curso de Licenciatura em Matemática da UNIOESTE e de seu respectivo Regulamento de Estágio e que subsidiam a organização/realização do Estágio Curricular Supervisionado; c) a reorganização da disciplina de Estágio Curricular Supervisionado a partir dos Planos de Ensino das disciplinas de Estágio I e II do ano letivo de 2020, dos relatórios finais dos alunos que realizaram o estágio no referido ano e das Atas da reunião de Colegiado do Curso de Matemática do ano de 2020; e d) por fim, as considerações finais considerando nossa pergunta norteadora e nosso objetivo de pesquisa.

\section{O Estágio Supervisionado na área de formação e atuação na Educação Básica: aspectos}




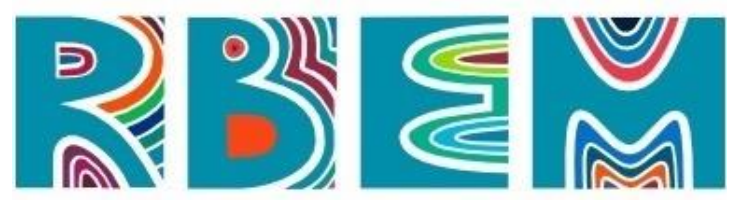

REVISTA BAIANA DE EDUCAÇĀO MATEMÁTICA

\section{legais}

A Resolução do Conselho Nacional de Educação CNE/CP n. ${ }^{\circ}$ 02, de $1 .^{\circ}$ de janeiro de 2015, instituiu as Diretrizes Curriculares Nacionais para a Formação de Professores e foi revogada pela Resolução do Conselho Nacional de Educação CNE 02/2019 - que definiu as Diretrizes Curriculares Nacionais à Formação Inicial em Nível Superior de Profissionais do Magistério para a Educação Básica - e a Base Nacional Comum para essa formação (BNCFormação). Faz-se oportuno destacar que os cursos de licenciatura têm o prazo de dois anos, a partir da publicação da Resolução CNE 02/2019, para atender à nova resolução, no entanto, ainda estão ocorrendo discussões e há um movimento para que a resolução seja revogada ou postergada a sua implantação.

Logo, os cursos de licenciatura, em sua maioria, estão organizados segundo a 'antiga' resolução (BRASIL, 2015). Este estudo corrobora com Dourado (2015) no tocante à referida Resolução quando destaca que esta possibilita maior organicidade das políticas, pois "[...] enfatizam que estes processos implicam o repensar e o avançar nos marcos referenciais atuais para a formação inicial e continuada" e visa "[...] ações mais orgânicas entre as políticas e gestão para a educação básica e a educação superior, incluindo a pós-graduação e, nesse contexto, para as políticas direcionadas à valorização dos profissionais da educação" (DOURADO, 2015, p. 306).

Em Brasil (2015), no artigo 13, parágrafo primeiro, prevê-se que "Os cursos de que trata o caput terão, no mínimo, 3.200 (três mil e duzentas) horas de efetivo trabalho acadêmico, em cursos com duração de, no mínimo, 8 (oito) semestres ou 4 (quatro) anos, compreendendo:"

I - 400 (quatrocentas) horas de prática como componente curricular, distribuídas ao longo do processo formativo;

II - 400 (quatrocentas) horas dedicadas ao estágio supervisionado, na área de formação e atuação na educação básica, contemplando também outras áreas específicas, se for o caso, conforme o projeto de curso da instituição;

III - pelo menos 2.200 (duas mil e duzentas) horas dedicadas às atividades formativas estruturadas pelos núcleos definidos nos incisos I e II do artigo 12 desta Resolução, conforme o projeto de curso da instituição;

IV - 200 (duzentas) horas de atividades teórico-práticas de aprofundamento em áreas específicas de interesse dos estudantes, conforme núcleo definido no inciso III do artigo 12 desta Resolução, por meio da iniciação científica, da iniciação à docência, da extensão e da monitoria, entre outras, consoante o projeto de curso da instituição (BRASIL, 2015, p. 01). 


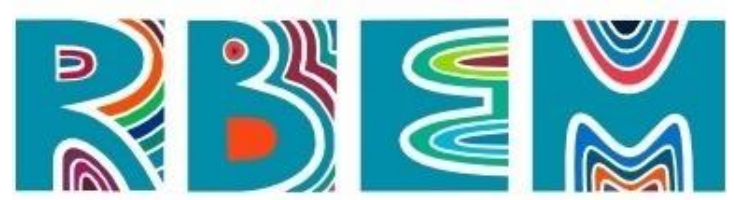

REVISTA BAIANA DE EDUCAÇÃO MATEMÁTICA

Conforme a Resolução, das 3200 (três mil e duzentas) horas mínimas, que visam à Formação Inicial de professores para a Educação Básica em Nível Superior, é obrigatório que 400 (quatrocentas) dessas horas sejam destinadas ao estágio supervisionado da referida área de atuação.

Pimenta (2016) considera que as 400 (quatrocentas) horas de prática como componente curricular, distribuídas ao longo do processo formativo, deveriam ser unidas com as 400 (quatrocentas) horas dedicadas ao estágio supervisionado. Diante disso, os cursos de licenciatura teriam 800 (oitocentas) horas dedicadas ao estágio, evitando possíveis utilizações equivocadas da carga horária da prática como componente curricular.

Em Brasil (2015) “O estágio curricular supervisionado é componente obrigatório da organização curricular das licenciaturas, sendo uma atividade específica intrinsecamente articulada com a prática e com as demais atividades de trabalho acadêmico". Esta definição evidencia que o estágio pode (e deveria ser) um princípio norteador do curso de Formação Inicial de professores, inclusive sendo possível o seu início já no primeiro ano do curso, no entanto, isto, na prática não ocorre.

A referida concepção de estágio corrobora com os estudos de Pimenta e Lima (2010) quando estas afirmam que este deve ser compreendido como um campo de conhecimento, pois a atividade docente é, ao mesmo tempo, prática e ação. O Estágio Curricular Supervisionado da Licenciatura em Matemática na UNIOESTE está organizado segundo Brasil (2015) e será apresentado a seguir.

\section{A organização do Estágio Curricular Supervisionado da Licenciatura em Matemática na UNIOESTE - campus de Foz do Iguaçu}

Neste item, discute-se a organização do Estágio Curricular Supervisionado do Curso de Licenciatura em Matemática da UNIOESTE. Para tanto, apresentamos uma pesquisa documental na qual analisamos a Resolução n. ${ }^{\circ}$ 220/2016 - Conselho de Ensino, Pesquisa e Extensão (CEPE) - que dispõem a respeito do Projeto Pedagógico do Curso (PPC), projeto esse cuja implementação iniciou-se em 2017 e foi organizado/elaborado seguindo as orientações de Brasil (2015) - conforme já denotado.

O PPC (PARANÁ, 2016) prevê o total de 408 (quatrocentas e oito) horas dedicadas ao 


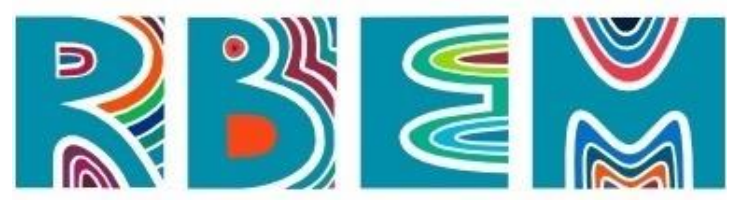

REVISTA BAIANA DE EDUCAÇÃO MATEMÁTICA

estágio e as divide em duas disciplinas de estágio, tendo 8 horas a mais que o mínimo obrigatório. As disciplinas, de igual carga horária cada, são intituladas Estágio Curricular Supervisionado I, ministrada no 3..$^{\circ}$ ano, e Estágio Curricular Supervisionado II, ministrada no 4. ${ }^{\circ}$ ano.

Na ementa da disciplina de Estágio Curricular Supervisionado I consta:

Análise, discussão e reflexão do sistema escolar da Educação Básica. Realização de estágio na forma de observação, participação e regência, de modo a desenvolver ações que valorizem o trabalho coletivo, realizem atividades de planejamento e atendam o projeto pedagógico da escola. Observação e participação no $1^{\circ}, 2^{\circ}, 3^{\circ}, 4^{\circ}$ e $5^{\circ}$ ano do Ensino Fundamental. Elaboração e execução de planos de trabalho docente no $6^{\circ}, 7^{\circ}, 8^{\circ}$ e $9^{\circ}$ ano do Ensino Fundamental, e a implementação de projetos visando à interdisciplinaridade e multidisciplinaridade tendo como foco norteador a disciplina de Matemática (PARANÁ, 2016, p. 13).

Já a ementa da disciplina "Estágio Curricular Supervisionado II" prevê:

Análise, discussão e reflexão dos elementos constitutivos do sistema escolar do Ensino Médio. Realização de estágio na forma de observação, participação e regência, de modo a desenvolver ações que valorizem o trabalho coletivo, realizem atividades de planejamento e atendam o projeto pedagógico da escola. Implementação de projetos visando à interdisciplinaridade e multidisciplinaridade tendo como foco norteador os conteúdos estruturantes de Matemática para o Ensino Médio (PARANÁ, 2016, p. 15).

A disciplina de estágio I, desenvolvida no $3 .^{\circ}$ ano do curso, visa à aproximação dos acadêmicos com os anos iniciais e finais do Ensino Fundamental que compõem uma das etapas da Educação Básica. Já a disciplina de estágio II, desenvolvida no 4. ${ }^{\circ}$ ano, direciona as suas atividades visando a uma aproximação dos acadêmicos com a última etapa da Educação Básica, ou seja, o Ensino Médio.

Os professores das referidas disciplinas têm uma carga horária de atividade de ensino de 4 (quatro) horas semanais, embora a disciplina tenha 6 (seis) horas semanais e esse trabalho ocorre, conjuntamente, com o coordenador de estágio que possui uma carga horária administrativa de 12 (doze) horas semanais. O coordenador é o responsável por estabelecer as parcerias com as instituições da Educação Básica que devem ser públicas, além de organizar toda a documentação dos estagiários. É, também, o responsável direto por definir como serão 


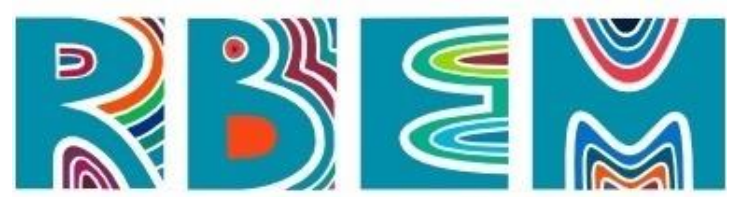

distribuídas as cargas horárias que devem, obrigatoriamente, abranger as atividades apresentadas na Figura 1, exposta a seguir:

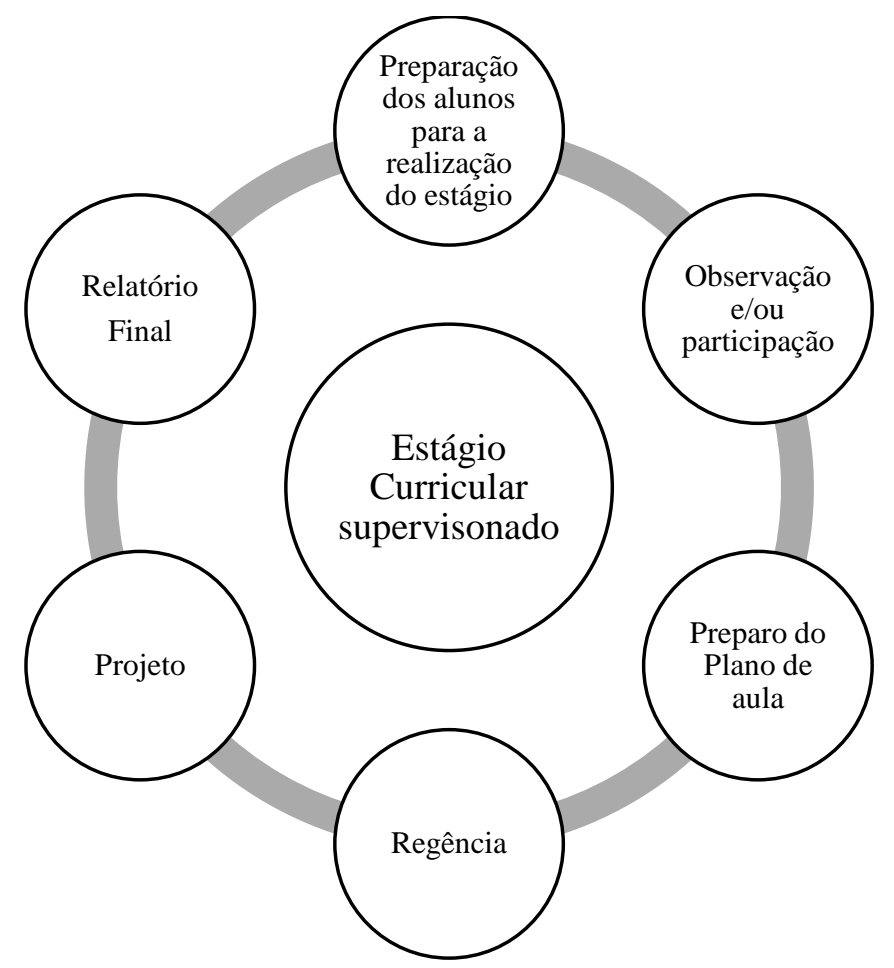

Figura 1: Atividades que compõem a disciplina de estágio, elaborado pelos autores.

Conforme a Figura 1, as disciplinas de Estágio Curricular Supervisionado são compostas pelas atividades de observação, orientação do planejamento, projeto e regência, além das aulas semanais realizadas na universidade para o estudo/reflexão dos aportes teóricos que servirão de base à elaboração das atividades desenvolvidas nas instituições de ensino.

Esse momento de preparação dos acadêmicos para a realização do estágio, que ocorre nas referidas aulas semanais, vão ao encontro com o exposto por Pimenta e Lima (2011) quando afirmam o papel da teoria como subsídio à reflexão, das interações entre os professores, os alunos e os conteúdos educativos, em geral para a formação humana, bem como as que "[...] estruturam os processos de ensino e aprendizagem” e, indo além, “[...] nas quais se atualizam os diversos saberes pedagógicos do professor e nas quais ocorrem os processos de reorganização e ressignificação de tais saberes" (PIMENTA; LIMA, 2011, p. 


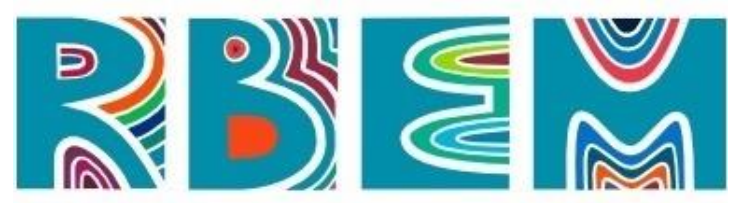

REVISTA BAIANA DE EDUCAÇÃO MATEMÁTICA

43).

Com relação à observação e/ou participação, o Regulamento de Estágio destaca que “[...] a observação consiste em apenas observar a aula dada pelo docente e a participação consiste em colaborar com o docente durante a aula quando solicitado pelo mesmo" (PARANÁ, 2014, p. 05). Segundo Estrela (2008):

[...] A observação de situações educativas continua a ser um dos pilares da formação de professores, no entanto, as perspectivas actuais da sua utilização implicam uma ruptura metodológica em relação à observação da lição-modelo praticada nos sistemas tradicionais. [...] Observação espontânea, não requerendo treino prévio do observador, deixa o estagiário entregue a si próprio: às suas projeções, aos seus fantasmas, aos seus quadros conceptuais mais ou menos limitados e limitadores (ESTRELA, 2008, p. 57).

Considerando as atividades de observação/participação, bem como das aulas semanais realizadas na disciplina de estágio, os alunos desenvolverão a atividade de regência e, para isto, devem preparar planos de aulas sendo orientados por um professor da universidade (o orientador de estágio).

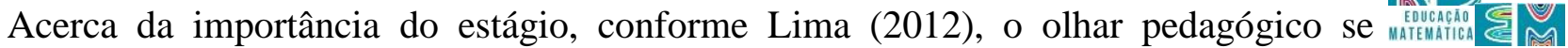
coloca para nós como atitude complexa, que acompanha o processo de aprendizagem contínua da profissão docente. Dessa forma, a passagem do estagiário pela escola campo é um espaço de autoformação e pode acrescentar elementos identitários no tocante à investigação dos fenômenos subjetivos que compõem o ser e o estar na profissão docente (LIMA, 2012, p. 68).

As disciplinas de estágio também preconizam o desenvolvimento de um minicurso (projeto) que, conforme o Regulamento de Estágio “[...] serão preparados em sala de aula, com o docente responsável pela disciplina e abrangerá temas das Diretrizes Curriculares de Matemática para Educação Básica do Paraná” (PARANÁ, 2014, p. 06).

Ao final de cada semestre, sendo que a disciplina de estágio é anual, os alunos devem, também, elaborar e entregar um relatório final no qual devem ser inseridos todos os documentos e atividades desenvolvidas no decorrer da disciplina. O conteúdo do mesmo é baseado nas atividades já citadas (observações, participação, projeto, preparo da regência e regência). 


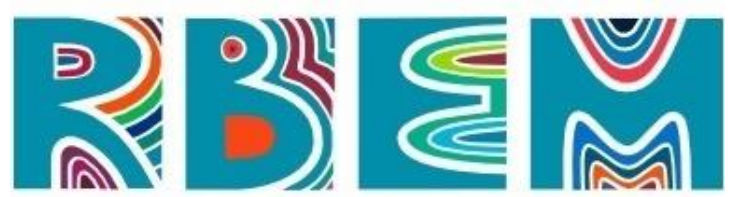

REVISTA BAIANA DE EDUCAÇÃO MATEMÁTICA

Segundo a Paraná (2014), as cargas horárias de cada atividade de estágio são definidas anualmente no Plano de Ensino da disciplina. Cumpre lembrar que as instituições de ensino nas quais são desenvolvidas a observação e/ou participação, a regência e o projeto, são escolhidas pelos estagiários matriculados nas disciplinas de estágio; seguidamente, o coordenador de estágio visita a instituição e dialoga com o professor de Matemática e a equipe pedagógica para verificar a disponibilidade em acolher o acadêmico.

Contudo, em 16 de março de 2020 foi editado pela Reitoria da UNIOESTE o Ato Executivo n. ${ }^{\circ}$ 21/2020, determinando a suspensão das atividades acadêmicas presenciais em virtude da pandemia da Covid-19, o que acarretou o fechamento dos diversos campi, impossibilitando que qualquer pessoa (aluno, professor ou agente universitário) frequentasse o local. Assim, no próximo item serão apresentadas as mudanças realizadas nas atividades do Estágio Curricular Supervisionado da UNIOESTE para possibilitar a sua realização no ano letivo de 2020.

(Re)organização do Estágio Curricular Supervisionado da Licenciatura em Matemática na UNIOESTE - campus de Foz do Iguaçu frente à pandemia da Covid-19

Para apresentar a (re) organização do Estágio Curricular Supervisionado da

Licenciatura em Matemática na UNIOESTE frente à pandemia da Covid-19, realizamos uma pesquisa documental a partir dos documentos esquematizados no Quadro 1.

Quadro 1: Guia de documentos analisados para verificar a (re) organização do estágio do Curso de Matemática

\begin{tabular}{|c|c|c|}
\hline Documentos & Ano & Localização \\
\hline $\begin{array}{l}\text { Resolução } \text { n }^{\circ} .002 / 2020 \text {, de } 16 \\
\text { de abril de } 2020 \text {, do Conselho } \\
\text { de Ensino, Pesquisa e } \\
\text { Extensão } \quad \text { (CEPE) } \\
\text { UNIOESTE. }\end{array}$ & 2020 & $\begin{array}{c}\text { https://www.unioeste.br/portal } \\
\text { /scs/cepe/editais }\end{array}$ \\
\hline $\begin{array}{l}\text { Decreto Estadual } \mathrm{n}^{\circ} 5283 \text {, de } \\
29 \text { de julho de 2020, que } \\
\text { regulamenta o estágio nos } \\
\text { Órgãos e Entidades da } \\
\text { Administração } \\
\text { Estadual Direta e Indireta, } \\
\text { incluindo as Instituições } \\
\text { Estaduais de Ensino Superior. }\end{array}$ & 2020 & $\begin{array}{c}\text { https://www.legislacao.pr.gov. } \\
\text { br/legislacao/pesquisarAto.do } \\
\text { ?action=exibir\&codAto }=2373 \\
13\end{array}$ \\
\hline $\begin{array}{l}\text { Ata da reunião do Colegiado } \\
\text { do curso de Matemática. }\end{array}$ & 2020 & $\begin{array}{l}\text { UNIOESTE-Campus Foz do } \\
\text { Iguaçu }\end{array}$ \\
\hline $\begin{array}{l}\text { Relatório final das atividades } \\
\text { dos acadêmicos das }\end{array}$ & 2020 & $\begin{array}{l}\text { UNIOESTE-Campus Foz do } \\
\text { Iguaçu }\end{array}$ \\
\hline
\end{tabular}

Revista Baiana de Educação Matemática, v. 02, n. 01, p. 01/20, e202122, jan./dez., 2021. 


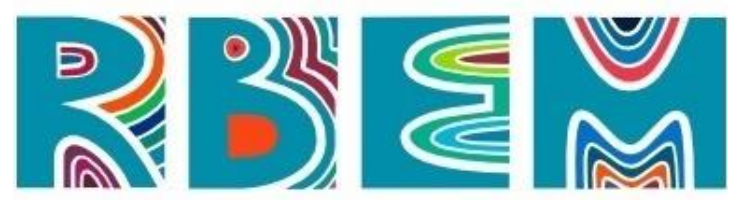

REVISTA BAIANA dE EDUCAÇÃo MATEMÁTICA

\begin{tabular}{|l|c|c|}
\hline disciplinas de estágio I e II. & & \\
\hline $\begin{array}{l}\text { Plano de ensino das } \\
\text { disciplinas de estágio I e II. }\end{array}$ & 2020 & $\begin{array}{c}\text { UNIOESTE-Campus Foz do } \\
\text { Iguaçu }\end{array}$ \\
\hline
\end{tabular}

Fonte: Elaborado pelos autores.

Segundo Saviani (2004), as fontes estão na origem, constituem o ponto de partida, a base, o ponto de apoio da construção historiográfica que é a reconstrução, no plano do conhecimento, do objeto histórico estudado. As fontes históricas não são a fonte da história, ou seja, não é delas que brota e flui a história. Elas, enquanto registros, enquanto testemunho dos atos históricos, são a fonte do nosso conhecimento histórico, isto é, é delas que brota, é nelas que se apoia o conhecimento que produzimos a respeito da história (SAVIANI, 2004, p. $5-6)$.

A Resolução n. ${ }^{\circ}$ 002/2020, de 16 de abril de 2020, do Conselho de Ensino, Pesquisa e Extensão (CEPE) da UNIOESTE estabeleceu que somente os cursos de graduação, que tenham previsão na modalidade em ensino à distância ou modalidade remota nos seus Projetos Político-Pedagógicos e Planos de Ensinos de Disciplina, com validade para todo o ano letivo de 2020, poderiam ofertar as atividades letivas ou trabalhos acadêmicos.

Considerando que o Curso de Licenciatura em Matemática, campus de Foz do Iguaçu, não atendia a tal exigência, então, nenhuma disciplina foi ofertada no primeiro semestre de 2020. No entanto, em 17 de agosto de 2020 foram iniciadas as atividades remotas pela Universidade após a regulamentação pela instituição. Ademais, o Decreto Estadual no 5283, de 29 de julho de 2020, regulamentou o estágio nos Órgãos e Entidades da Administração Pública Estadual Direta e Indireta, incluindo as Instituições Estaduais de Ensino Superior no período da pandemia da Covid-19.

Diante disso, o Colegiado do nosso Curso decidiu pela oferta das disciplinas de estágios I e II na modalidade remota entre os meses de agosto a dezembro de 2020. Para iniciar as referidas disciplinas foram necessárias mudanças. A primeira mudança ocorreu na atividade "Preparação dos alunos para a realização do estágio", cujas aulas semanais das disciplinas, no período supracitado, ocorreram por meio de interações síncronas via plataforma do Google Meet.

Além disso, foram (re)organizadas as estratégias para o desenvolvimento das 


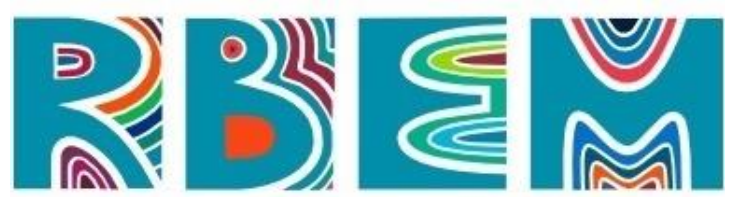

REVISTA BAIANA DE EDUCAÇÃO MATEMÁTICA

atividades de observação, regência e projeto (minicurso). Considerando a conjectura proveniente da pandemia, houve o diálogo com os estagiários indicando a impossibilidade da escolha da instituição de ensino de sua preferência, já que os critérios deveriam coadunar com as condições impostas. A coordenadora de estágio visitou as instituições de ensino da rede estadual e o Instituto Federal do Paraná (IFPR/campus de Foz do Iguaçu) objetivando conhecer a realidade das atividades de ensino das instituições na conjectura de pandemia. É importante destacar que todos os protocolos de segurança foram adotados. Partindo destas visitas e seguindo a legislação vigente, o estágio II e as suas respectivas atividades de observação e/ou participação e regência aconteceram no IFPR. Para discutir os encaminhamentos das referidas atividades houve um encontro com a coordenadora de ensino e os professores de Matemática do IFPR, professores da disciplina de estágio II e o coordenador de estágio da UNIOESTE via plataforma do Google Meet.

Iremos discorrer a respeito das atividades realizadas nas disciplinas de Estágio I e Estágio II e para tal dividiremos em duas seções, a saber: disciplina de Estágio I e disciplina de Estágio II.

\section{Disciplina de Estágio I}

As atividades do Estágio I, do tipo regência e observação e/ou participação, ocorreram em três instituições da rede estadual de ensino. Já para a realização do projeto (minicurso), além das instituições mencionadas anteriormente, também foi necessário o estabelecimento de parceria com uma instituição da rede privada. Considerando os trâmites legais da rede estadual de ensino, os estagiários e orientadores da universidade receberam um e-mail @escola possibilitando, assim, o acesso à plataforma da rede estadual de ensino. A partir disso, os estagiários foram inseridos nas turmas dos professores em que se desenvolveriam as atividades de observação e/ou participação, regência e projeto. Conforme os relatórios dos estagiários da disciplina de estágio I, bem como nas Atas das reuniões do Colegiado do Curso de Matemática, essa etapa de autorização para o acesso à referida plataforma causou muita preocupação devido à burocracia que vislumbrava que a liberação dos estagiários, para o início do estágio, não se efetivaria como no presencial e no tempo hábil para a finalização da disciplina. 


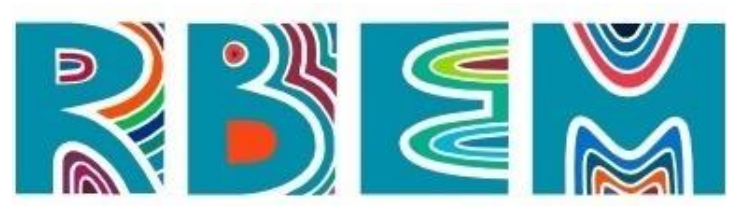

REVISTA BAIANA DE EDUCAÇÃo MATEMÁTICA

Ainda na disciplina de estágio I, para o desenvolvimento da atividade observação e/ou participação ficou estabelecido que os estagiários poderiam desenvolver o estágio individualmente ou em duplas. Considerando o objetivo da atividade que reside no conhecimento da instituição de ensino na qual o estágio se desenvolveria remotamente, foi proposta a leitura do Projeto Pedagógico do Curso (PPC) da referida instituição, além de solicitar aos acadêmicos que visitassem o seu entorno, como apresentado na Figura 2; além disso, os estagiários responderam questões a respeito das possíveis contribuições do colégio à região em que está inserido.

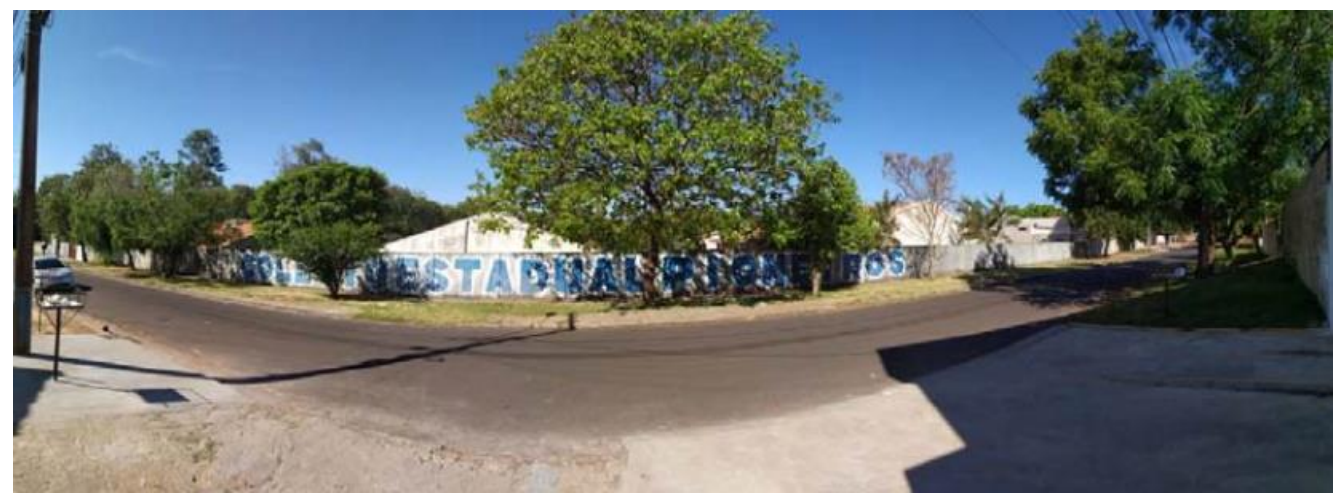

Figura 2: Imagem do entorno da instituição de ensino atividade observação e/ou participação, acervo dos autores.

Nos relatórios finais da disciplina de estágio I houve consenso entre os estagiários que a visita ao entorno do colégio contribuiu para direcionar o olhar-conhecimento, na compreensão da organização do trabalho a ser desenvolvido pelo professor. Outro ponto destacado foi a impossibilidade de conhecer as instalações internas do colégio devido às restrições impostas pela pandemia causada pela Covid-19.

Dando continuidade à atividade observação/participação, foram convidadas duas professoras de Matemática da rede estadual de ensino que receberam (virtualmente) os estagiários e promoveram discussões de forma síncrona na aula da disciplina de estágio, o que contribuiu para ampliar o conhecimento a respeito do entorno do colégio. Esse 'encontro' vai ao encontro do exposto por Lima (2012), pois “[...] conhecer a profissão e seus profissionais aproxima-nos do magistério, levando-nos a perceber as possibilidades e limites do trabalho desenvolvido pelos professores na realidade do cotidiano escolar”; assim, “[...] o estágio supervisionado pode ser esse espaço e o estudo da memória docente, um instrumento de 


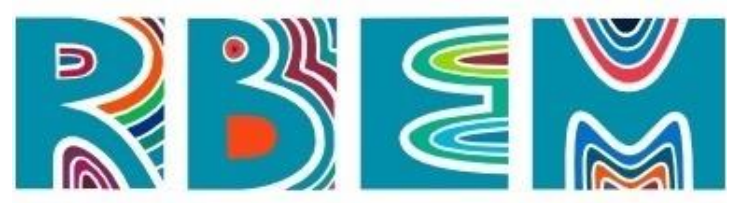

formação" (LIMA, 2012, p. 68).

Dando continuidade ao desenvolvimento da atividade observação e/ou participação da disciplina de estágio I, os estagiários ficaram responsáveis por elaborar os materiais visando à interação assíncrona via plataforma Google Classroom, conforme apresentado na Figura 3.

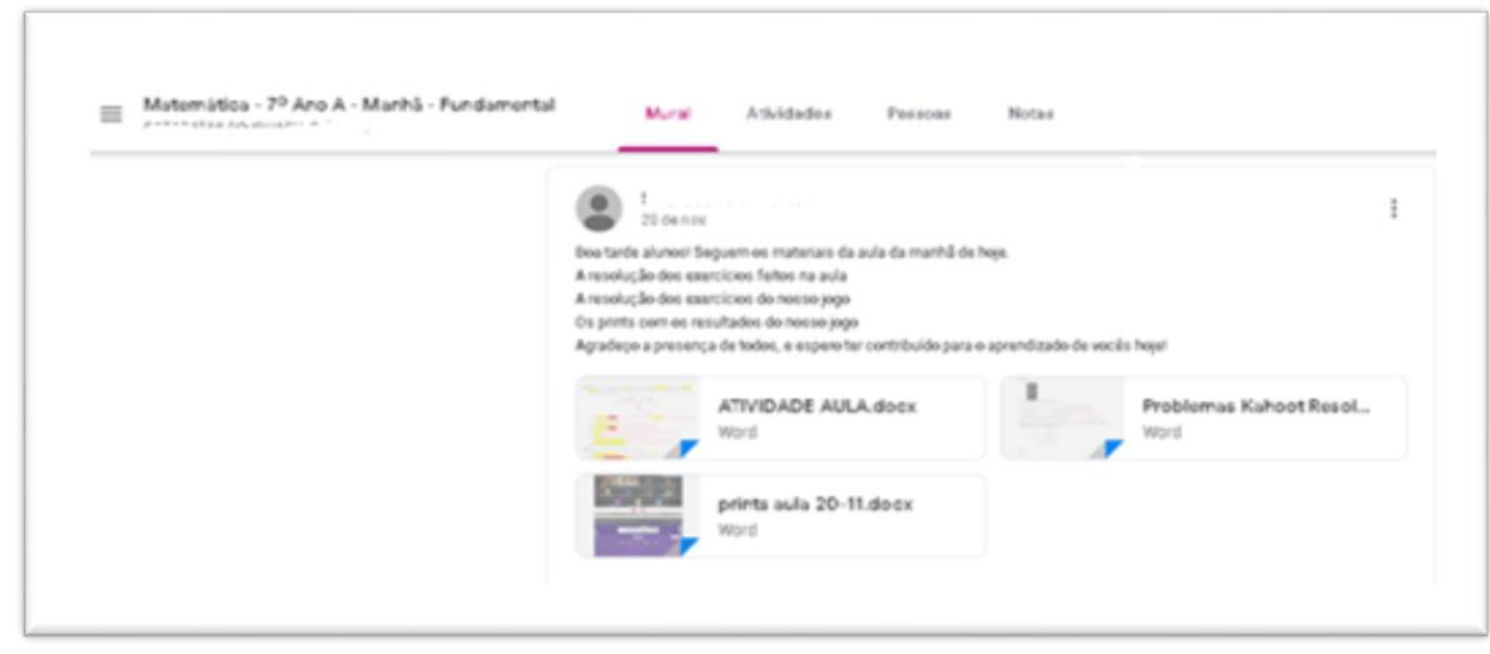

Figura 03: Layout da plataforma Google Classroom - interação assíncrona, acervo dos autores.

Os estagiários, em seus relatórios finais, destacaram que as interações assíncronas favoreceram a exploração de software para a gravação e edição de aula e vídeos de animações que, dificilmente, ocorreria se o estágio fosse presencial. A Figura 4 apresenta, por exemplo, o canal desenvolvido por uma das estagiárias.

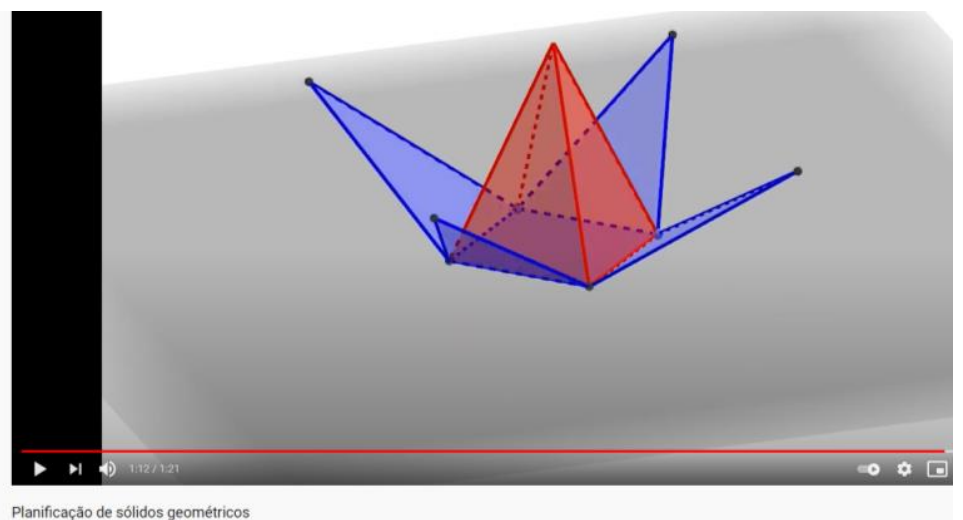

Figura 4: Layout do canal criado pela estagiária da disciplina de estágio I, acervo dos autores. 


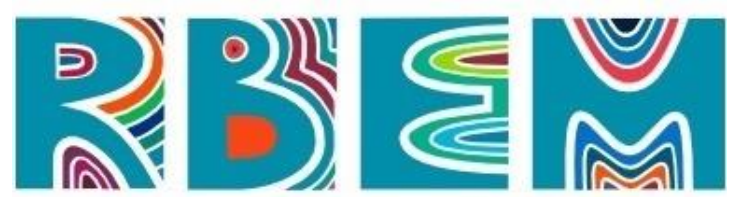

REVISTA BAIANA DE EDUCAÇÃO MATEMÁTICA

Mediante o exposto, a atividade de observação e/ou participação na disciplina de estágio I resumiu-se a organização da aula visando a interações assíncronas pela plataforma Google Classroom, visitas ao entorno do colégio e diálogo com as professoras da rede estadual.

Outro desafio imposto foi o desenvolvimento da atividade de regência. A orientação com o professor orientador da universidade, para elaboração do plano de aula, ocorreu por meio de interação síncrona, via plataforma Google Meet assim como a aula realizada com os alunos. Nos relatórios dos estagiários, ficaram evidentes que as dificuldades de conexões dos alunos da Educação Básica trouxeram implicações para o desenvolvimento da regência e, também, os diferentes elementos que acabam distraindo os alunos da Educação Básica, visto que os mesmos, em sua maioria, não têm espaço adequado em suas residências para assistir às aulas, o que pode ter contribuído para a pouca participação nas aulas regidas pelos estagiários.

Com relação às atividades do projeto que preconizam o desenvolvimento do minicurso na instituição de ensino, a mesma ocorreu ao mesmo tempo, em que foram realizadas as demais atividades da disciplina de estágio. Isso ocorreu, inclusive, pelo fato do curto período de tempo para a finalização da referida disciplina. Para tanto, houve uma (re) organização permitindo que as interações síncronas se efetivassem via plataforma Google Meet, tendo sido utilizados grupos criados no WhatsApp para a ocorrência de interações assíncronas viabilizando, assim, a comunicação entre os estagiários e os alunos das instituições estaduais.

Cumpre lembrar que durante a disciplina de estágio I também houve a necessidade de reorganizar a atividade observação e/ou participação nos anos iniciais do Ensino Fundamental. Desse modo, foi proposta a análise do Referencial Curricular do Paraná (2018) e, também, foi convidado um professor dos anos iniciais para discutir a respeito dos desafios do trabalho docente neste nível de ensino, no atual momento pandêmico, na aula da disciplina de estágio I.

\section{Disciplina de Estágio II}

No que tange às atividades (minicurso, observação e regência) que compõem parte da referida disciplina (conforme já discorrido), fizeram-se necessárias adaptações tendo em vista 


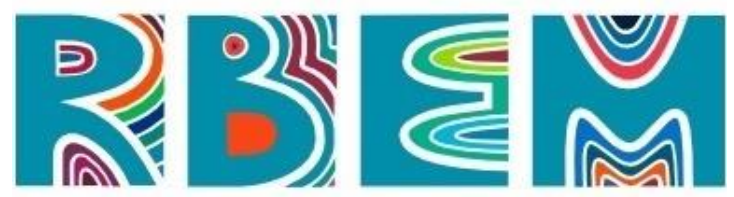

REVISTA BAIANA DE EDUCAÇÃO MATEMÁTICA

a impossibilidade de os acadêmicos estarem fisicamente nas instituições de ensino da Educação Básica.

$\mathrm{Na}$ atividade de minicurso, os acadêmicos ministraram cursos abordando diversos conteúdos matemáticos a alunos da Educação Básica (anos finais do Ensino Fundamental e Ensino Médio). Uma parte dos acadêmicos realizou os minicursos em um colégio particular do município de Foz do Iguaçu. Os professores responsáveis pela disciplina firmaram um projeto com a coordenadora e a diretora do referido colégio de modo a viabilizar a ocorrência destas atividades. Neste colégio, os acadêmicos foram divididos em trios e cada trio fícou responsável pela elaboração de minicursos e em atender às dúvidas dos alunos referentes aos conteúdos matemáticos.

Os encontros entre os acadêmicos e os alunos do colégio deram-se remotamente, via utilização da plataforma Google Meet. Também, foram criados grupos no WhatsApp, um para cada trio de acadêmicos, de modo a aproximar e "se tornar" um meio de comunicação entre os alunos do colégio e os acadêmicos. Ainda, sobre a atividade de minicurso, outro trio de acadêmicos atuou na elaboração de minicursos abordando os conteúdos matemáticos do Ensino Médio, de modo a auxiliar os alunos da Educação Básica pública que prestariam o vestibular (e o ENEM) ao final do referido ano. Esse trio postou, semanalmente, videoaula, na plataforma YouTube, durante quatro meses. Um grupo no WhatsApp também foi criado de modo a auxiliar os alunos que assistiam as referidas videoaulas.

Para a realização das atividades de observação e regência, firmou-se um convênio junto ao Instituto Federal do Paraná (IFPR), campus de Foz do Iguaçu. A diretora de ensino do IFPR possibilitou uma reunião, via plataforma Google Meet, com os professores de Matemática do Instituto. A atividade de observação se deu mediante a leitura-análise do Projeto Político Pedagógico do IFPR. Na impossibilidade de uma visita in loco ao Instituto, por meio da referida leitura-análise fez-se possível o conhecimento, pelo acadêmico, da “estrutura” física, administrativa e político-pedagógica do IFPR. No que concerne à atividade de regência, cada acadêmico ficou responsável por uma turma do Ensino Médio Técnico. Os professores de Matemática dessas turmas distribuíram, entre os acadêmicos, os conteúdos de Matemática que foram abordados nas regências.

Antes da ocorrência das regências, cada acadêmico desenvolveu as seguintes 


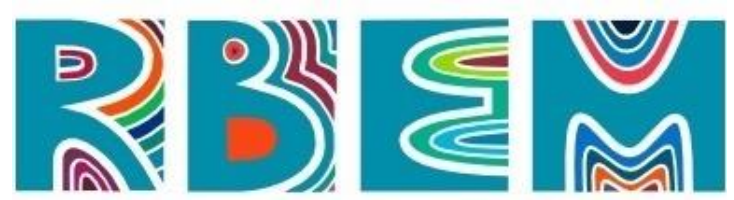

REVISTA BAIANA DE EDUCAÇÃO MATEMÁTICA

atividades: a) elaboração do plano de aula; b) elaboração de uma videoaula referente ao conteúdo matemático solicitado; c) elaboração de problemas matemáticos sobre o conteúdo trabalhado.

Os professores de Matemática do Instituto auxiliaram os acadêmicos na postagem das atividades b) e c) na plataforma Moodle, sendo essa a plataforma utilizada pelo IFPR ao/para o desenvolvimento das atividades de ensino na modalidade remota.

Nos dias de regência, que totalizaram duas aulas para cada acadêmico, com duração de uma hora cada, o acadêmico, juntamente com o professor de Matemática do Instituto e os alunos das turmas, realizou um encontro síncrono, via plataforma Google Meet. Neste período-encontro, o acadêmico resolveu os problemas matemáticos anteriormente propostos (item c) e sanou as dúvidas dos alunos a respeito do conteúdo matemático abordado na videoaula (item b).

Mediante a leitura-análise dos relatórios elaborados pelos acadêmicos matriculados da disciplina de estágio II, foi possível identificar alguns aspectos. De acordo, com os acadêmicos salientaram que a realização do estágio, na forma remota, implicou no aumento de trabalho uma vez que a preparação do material a ser disponibilizado na plataforma aos alunos, bem como a elaboração das videoaulas, dispendem um maior tempo se comparada à realização do estágio na forma presencial. A Figura 5 apresenta o canal elaborado pelo grupo de estagiárias da disciplina.

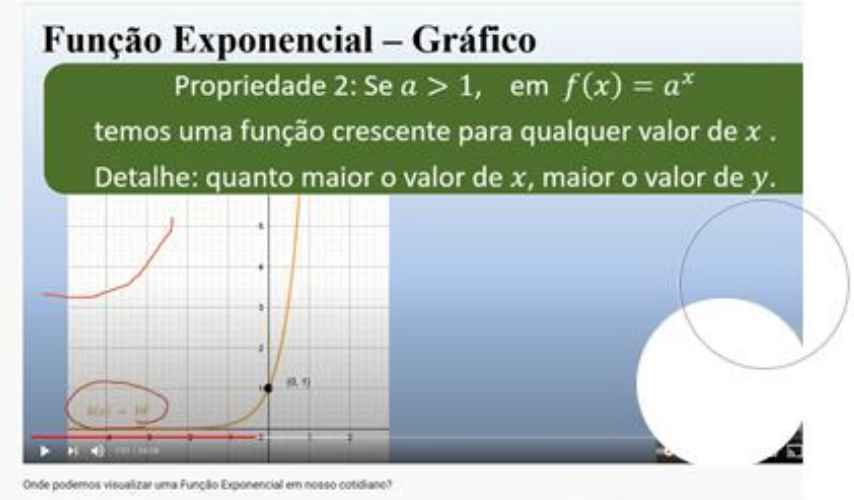

Figura 5: Layout do canal criado pelo grupo de estagiárias da disciplina de estágio II, acervo dos autores. 


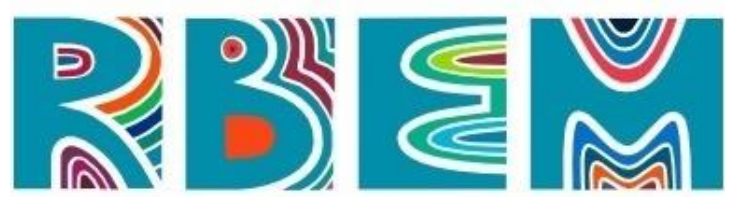

REVISTA BAIANA DE EDUCAÇÃO MATEMÁTICA

Como indicado pelos acadêmicos em seus relatórios, a realização do estágio na forma remota possibilitou diversas aprendizagens no tocante à utilização das tecnologias da informação e da comunicação ao/para o ensino. Outro aspecto levantado nos relatórios dos estagiários foi que embora os alunos do IFPR tenham participado dos encontros síncronos, tal participação foi relativamente baixa ainda mais se comparada às participações quando da realização da regência na forma presencial.

\section{Considerações Finais}

O presente trabalho apresentou a (re) organização do Estágio Curricular Supervisionado do Curso de Licenciatura em Matemática na UNIOESTE frente à pandemia da Covid-19. Para tanto, desenvolveu-se uma pesquisa qualitativa de cunho bibliográfica e documental. Constata-se que o curso analisado segue as orientações de Brasil (2015), cuja carga horária de estágio (408 horas) está distribuída em duas disciplinas anuais, sendo elas: Estágio Supervisionado I, no terceiro ano do curso, e Estágio Supervisionado II, no quarto ano.

A pesquisa documental evidenciou que as disciplinas de estágio I e II são compostas pelas atividades de observação, orientação do planejamento, projeto e regência, além das aulas semanais realizadas na universidade para o estudo/reflexão dos aportes teóricos que servirão de base à elaboração das atividades desenvolvidas nas instituições de ensino.

Cabe salientar que, em decorrência da pandemia, o Estado do Paraná teve de adequar a sua legislação de modo a possibilitar a ocorrência das atividades de ensino nas instituições educativas. A partir de tal adequação, em agosto do ano de 2020, a Universidade precisou, também, se readequar, estabelecendo novas formas para o desenvolvimento das atividades de ensino nos cursos por meio da forma remota. Partindo destas regulamentações-readequações, das discussões realizadas pelo Colegiado do Curso de Licenciatura em Matemática e do diálogo com os alunos matriculados nas disciplinas de Estágio Supervisionado I e II, propôsse a sua retomada buscando contribuir com a continuidade das atividades de ensino. Faz-se oportuno destacar que houve uma mudança no desenvolvimento das atividades de observação e/ou participação, regência e projeto, dado que os discentes estagiários não puderam escolher a instituição de ensino devido às previsões legais da conjectura da Covid-19 que indicava que 


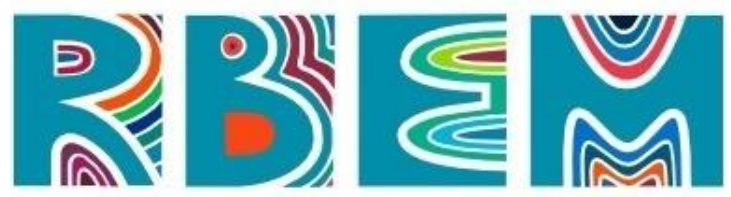

REVISTA BAIANA DE EDUCAÇÃO MATEMÁTICA

esta responsabilidade era do Núcleo Regional de Educação.

No entanto, esta (re) organização oportunizou a aproximação da professora da rede estadual na disciplina de estágio quando a mesma contribuiu com a atividade de observação e/ou participação, conforme destacado anteriormente. Outro ponto importante foi a possibilidade dos estagiários se aproximarem de diversas aprendizagens no tocante à utilização das tecnologias da informação e da comunicação ao/para o ensino como as plataformas de aprendizagem, que dificilmente ocorreria no estágio presencial, o que acabou permitindo fazer uma reflexão das dificuldades do trabalho docente nas interações síncronas/assíncronas em tais plataformas e como os professores tornaram-se responsáveis, individualmente, em solucionar os problemas estruturais na educação escolar que a pandemia da Covid-19 tornou ainda mais evidente.

A partir de reflexões a respeito da experiência supracitada, faz-se possível destacar as possibilidades de fomentar a utilização das plataformas de aprendizagem mesmo quando do retorno ao ensino presencial, seja para a realização das atividades a serem desenvolvidas na/pelas disciplinas de estágio, bem como para as atividades de regência elaboradas e executadas pelos acadêmicos junto aos alunos da Educação Básica.

Enfim, o estágio do curso de Licenciatura em Matemática da UNIOESTE foi desenvolvido no ano de 2020 apesar da pandemia e seguindo as previsões legais. Todo esse contexto acarretou mais morosidade nos trâmites para o início das atividades de observação e/ou participação, regência e projeto e, ainda, não tornou possível a realização do estágio na modalidade presencial. Os professores das disciplinas de estágio e a coordenação entendem a importância da realização do estágio na modalidade presencial, mas considerando a conjectura e que o retorno presencial das aulas seguramente ainda é incerto, a (re) organização das atividades de estágio foi o melhor caminho possível e escolhido.

\section{Referências}

BRASIL. Lei Federal $n .^{\circ}$ 13.979/2020. Dispõe sobre as medidas para enfrentamento da emergência de saúde pública de importância internacional decorrente do coronavírus responsável pelo surto de 2019. Publicada em 12. mar. 2021. 


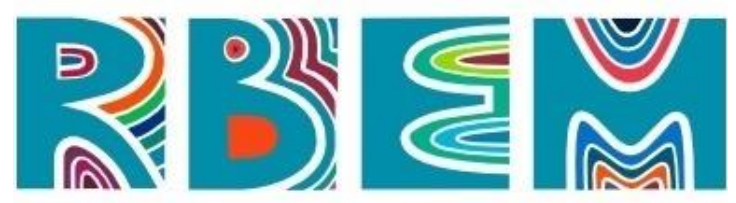

REVISTA BAIANA DE EDUCAÇÃO MATEMÁTICA

BRASIL. Resolução $n^{o}$ 1/2002. Institui Diretrizes Curriculares Nacionais para a Formação de Professores da Educação Básica, em nível superior, curso de licenciatura, de graduação plena. Brasília, 18 de fevereiro de 2002. Brasília, 2002. Disponível em < http://portal.mec.gov.br/cne/arquivos/pdf/rcp01_02.pdf > Acessado em 29 mar. 2017.

BRASIL. Conselho Nacional de Educação. Resolução CNE/CP $n^{o} 2$, de $1^{o}$ de julho de 2015. Define as Diretrizes Curriculares Nacionais para a formação inicial em nível superior (cursos de licenciatura, cursos de formação pedagógica para graduados e cursos de segunda licenciatura) e para a formação continuada. Disponível em $<$ http://portal.mec.gov.br/index.php?option=com_docman\&view=download\&alias=70431res-cne-cp-002-03072015-pdf\&category_slug=agosto-2017-pdf\&Itemid=30192 >. Acessado em 29 mar. 2017.

CARVALHO, M. Estágio na Licenciatura em Matemática: observações nos anos iniciais. Petrópolis, RJ: Vozes, 2012.

ESTRELA, A. Teoria e Prática de Observação de Classes: uma estratégia de formação de professores. 4. ed. Portugal: Porto Editora, 2008.

LIMA, M. S. L. Estágio e aprendizagem da profissão docente. Brasília: Liber Livro, 2012.

PARANÁ. UNIOESTE. Resolução CEPE $n^{\circ} 127$ de 22 de maio de 2014. Aprova o regulamento das disciplinas de Estágio Supervisionado I e II do curso de Matemática, do campus de Foz do Iguaçu, 2014. Disponível em < http://www.unioeste.br/servicos/arqvirtual/arquivos/1272014-CEPE.pdf >. Acessado em 12.jan. 2021.

PARANÁ. UNIOESTE. Resolução $n^{o}$ 220/2016-CEPE Projeto Pedagógico de curso de Matemática - Licenciatura de curso de Matemática, do campus de Foz do Iguaçu, 2016. Disponível em < http://www.unioeste.br/servicos/arqvirtual/arquivos/2202016-CEPE.pdf > Acessado em: 12. jan. 2021.

PARANÁ. UNIOESTE. Resolução $N^{o}$ 74/2020-CEPE. Regulamenta as atividades de ensino remoto, em caráter excepcional, nos cursos de graduação presenciais da Unioeste, durante a suspensão das atividades acadêmicas letivas presenciais, determinadas pelo Ato Executivo $\mathrm{n}^{\circ}$ 21/2020-G RE. $\quad$ Disponível em https://midas.unioeste.br/sgav/arqVrtConteudo/download?arqCntCodigo=207601 >. Acessado em: 12. jan. 2021. 


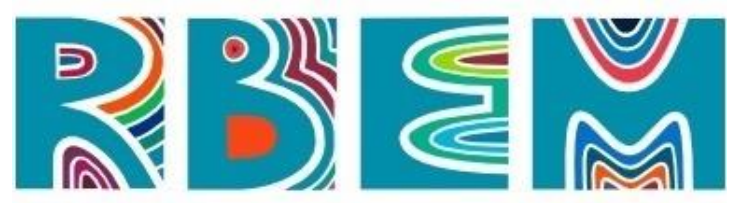

REVISTA BAIANA DE EDUCAÇÃO MATEMÁTICA

PARANÁ. Decreto Estadual n. 4.320/2020. Dispõe sobre as medidas para enfrentamento da emergência de saúde pública de importância internacional decorrente do Coronavírus COVID-19. Publicado em 16 mar. 2020.

PARANÁ. Decreto Estadual $n^{\circ} 4.312 / 2020$. Concede licença especial, de acordo com o art. $4^{\circ}$ da Lei Complementar n. 217 de 22 de outubro de 2019, conforme especifica. Publicado em 30 mar. 2020.

PARANÁ. Lei Estadual $n^{\circ}$ 20.189/2020. Obriga, no Estado do Paraná, o uso de máscaras enquanto perdurar o estado de calamidade pública em decorrência da pandemia do coronavírus SARS-Cov-2, e adota outras providências. Publicada em 28 abr. 2020.

PIMENTA, S. G.; Lima, M. S. Estágio e Docência. 6. ed. São Paulo: Cortez. 2011.

PIMENTA, S. G. Em defesa de um ensino público e com qualidade. Entrevista concedida NONATO, C. Selma Garrido Pimenta: em defesa de um ensino público e com qualidade. Comunicação \& Educação, São Paulo, v. 21, n. 1, p. 97-107, jan./jun. 2016. Disponível em: <https://www.revistas.usp.br/comueduc/article/view/111520/112713 >. Acesso em: 02 out. 2017.

PIMENTA, S. G.; ALMEIDA, M. Docência Universitária: passos de um percurso formativo. I. In: PIMENTA, S. G.; ALMEIDA, M. I. de (org.). Pedagogia Universitária: caminhos para a formação de professores. São Paulo: Cortez, 2011. p.7-16.

SAVIANI, D. Breves considerações sobre fontes para a história da educação. In: LOMBARDI, J. C.; NASCIMENTO, M. I. M. (org.). Fontes, História e Historiografia da Educação. Campinas: Autores Associados, 2004. p. 1-12.

Artigo submetido em: 30/07/2021

Artigo aceito em: 06/10/2021 